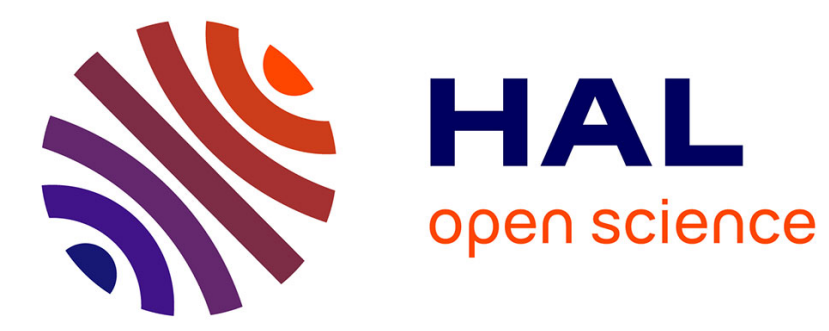

\title{
Nanophotonic polarization diversity demultiplexer chip
} van Laere Frederick, Tiziana Stomeo, Cyril Cambournac, Melanie Ayre, Romain Brenot, Henri Benisty, Günther Roelkens, Thomas F. Krauss, Dries van Thourhout, R. Baets

\section{- To cite this version:}

van Laere Frederick, Tiziana Stomeo, Cyril Cambournac, Melanie Ayre, Romain Brenot, et al.. Nanophotonic polarization diversity demultiplexer chip. Journal of Lightwave Technology, 2009, 27 (4), pp.417. hal-00567023

\section{HAL Id: hal-00567023 \\ https://hal-iogs.archives-ouvertes.fr/hal-00567023}

Submitted on 11 Sep 2013

HAL is a multi-disciplinary open access archive for the deposit and dissemination of scientific research documents, whether they are published or not. The documents may come from teaching and research institutions in France or abroad, or from public or private research centers.
L'archive ouverte pluridisciplinaire $\mathbf{H A L}$, est destinée au dépôt et à la diffusion de documents scientifiques de niveau recherche, publiés ou non, émanant des établissements d'enseignement et de recherche français ou étrangers, des laboratoires publics ou privés. 


\title{
Nanophotonic Polarization Diversity Demultiplexer Chip
}

\author{
Frederik Van Laere, Student Member, IEEE, Tiziana Stomeo, Cyril Cambournac, Melanie Ayre, \\ Romain Brenot, Henri Benisty, Member, IEEE, Günther Roelkens, Member, IEEE, Thomas F. Krauss, \\ Dries Van Thourhout, Member, IEEE, and Roel Baets, Fellow, IEEE, Member, OSA
}

\begin{abstract}
We demonstrate a very compact multifunctional photonic-crystal demultiplexer on high index contrast InP-membrane for coarse WDM applications. Polarization diversity is implemented using 2D-grating couplers. The performance of the device is evaluated using integrated p-i-n photodetectors. Polarization diversity from fiber to detector-without intermediate functional device-results in a minimal polarization dependent loss (PDL) of $0.2 \mathrm{~dB}$. This value increases to $1.1 \mathrm{~dB}$ when including the photonic-crystal demultiplexer.
\end{abstract}

Index Terms-CWDM, demultiplexer, integrated optics, photonic crystal, p-i-n photodetectors.

\section{INTRODUCTION}

$\mathbf{L}$ OW-COST devices for metropolitan optical networks are in high demand. To mass-produce them, the integration of several active and/or passive functions is highly desirable, which makes the nanophotonics approach very attractive. Isolated realizations of nanophotonic devices in the telecom wavelength range are numerous and extremely striking (nanocavities [1], [2], lasers [3], [4], microdiscs [4], [5], etc.), but integration has been hampered by a number of bottlenecks, for example i) the extreme polarization sensitivity of most etched nanostructures; ii) fiber coupling to narrow wavelength-scale waveguides or other tiny structures; iii) the difficulty of integrating passive and active parts as well as coupling between them; and iv) bandwidth/spectral uniformity requirements that meet the strict demands of system engineers. Photonic crystals $(\mathrm{PhC})$ exhibit virtually all of the above bottlenecks and most strikingly, polar-

Manuscript received March 21, 2008. Current version published February 13, 2009. This work was supported in part by the European Union under the FP6IST-004582 FUNFOX project. F. Van Laere acknowledges the Institute for the Promotion of Innovation through Science and Technology (IWT Flanders) for a scholarship

F. Van Laere, G. Roelkens, D. Van Thourhout, and R. Baets are with the Department of Information Technology (INTEC), Ghent University-IMEC, B-9000 Gent, Belgium (e-mail: frederik.vanlaere@intec.ugent.be; gunther.roelkens@intec.ugent.be; dries.vanthourhout@intec.ugent.be; Roel.Baets@intec.ugent.be).

T. Stomeo and T. F. Krauss are with the School of Physics and Astronomy, University of St. Andews, St. Andrews, Fife, KY16 9SS, U.K. (e-mail: ts41@ st-andrews.ac.uk; tfk@st-andrews.ac.uk).

C. Cambournac, M. Ayre, and H. Benisty are with the Laboratoire Charles Fabry de l'Institut d'Optique, CNRS, Univ Paris-Sud, F-91127 Palaiseau, France (e-mail: cyril.cambournac@institutoptique.fr; melanie.ayre@ institutoptique.fr; henri.benisty@institutoptique.fr).

R. Brenot is with Alcatel-Thales III-V Lab, F-91767 Palaiseau Cedex, France (e-mail: romain.brenot@3-5lab.fr).

Color versions of one or more of the figures in this paper are available online at http://ieeexplore.ieee.org.

Digital Object Identifier 10.1109/JLT.2008.929414 ization dependence. They almost exclusively operate in TE polarization due to the favorable bandgap and its associated light control [6].

On the other hand, their polarization dependence can be turned into an advantage and be used for realizing the polarization diversity approach. By deploying a polarization diversity coupler [7], [8] and integrating it with a photonic-crystal demultiplexer as well as an array of integrated photodetectors, we can, in fact, address all of the bottlenecks mentioned above. We use a reliable polymer bonding technique [9] to create a high-index contrast InP membrane structure as our material platform. This choice for a high-index contrast layer structure is motivated by the ongoing trend towards further miniaturization and high density integration of optical components on a chip. Our integration effort is thus the first to combine system-grade functionality with the virtually exclusive use of miniature nanophotonics elements to attain it.

The choice of InP-based technology over the more popular silicon-on-insulator (SOI) platform is motivated by the need for integrating active elements. While SOI has advanced in several respects [10]-[14], and both spectrograph type WDM demultiplexers like arrayed-waveguide gratings (AWG) [15]-[17] and $\mathrm{PhC}$ type demultiplexers [18], [19] have now been demonstrated, realizing active components remains a major challenge. Germanium photodiodes epitaxially grown on silicon have been demonstrated [20], but this approach is not suited for making lasers. Using heterogeneous integration of III-V on $\mathrm{Si}$, both lasers and detectors have been demonstrated [21]-[23]. In our approach, both active and passive devices are implemented in the same III-V material, and there is no need to combine different material systems in order to realize active-passive functionality.

In the following sections, we describe the realization of a polarization diversity demultiplexer chip with integrated photodetectors on InP-membrane. First results were outlined in [24]. Here, we go into detail with a focus on integration technology and polarization diversity analysis of the device. The performance of detectors, demultiplexer, and polarization diversity gratings is investigated first by evaluating device subsets before combining the complete set of functions into the final component.

\section{Device Layout}

The device layout is shown in Fig. 1(a) and the different building blocks in Fig. 1(c)-(f). The basic layer stack is a 300-nm-thick InP-membrane sandwiched between air and benzocyclobutene $(\mathrm{BCB}$, a polymer whose refractive index is $n=$ 
(a)

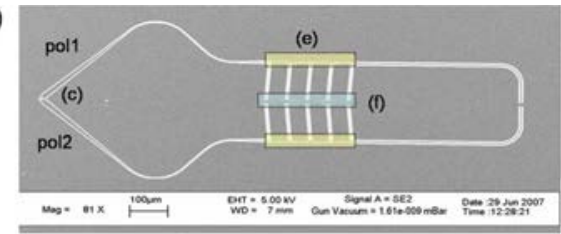

(c)
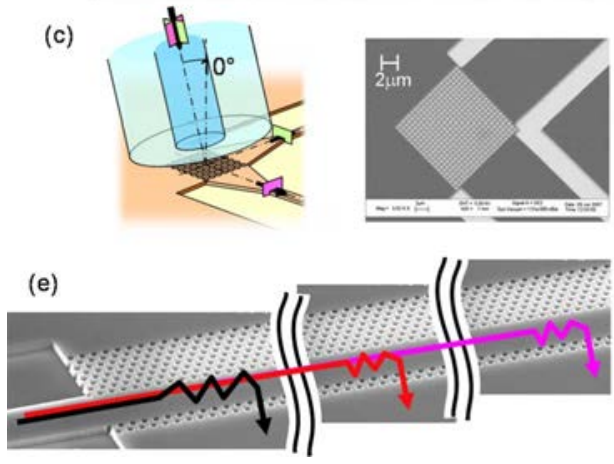

(b)

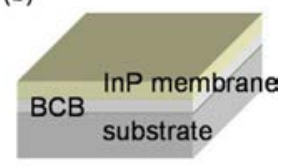

(d)
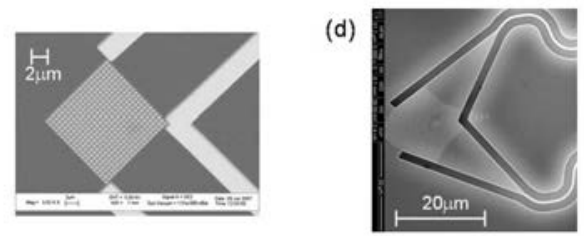

(f)

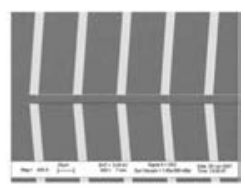

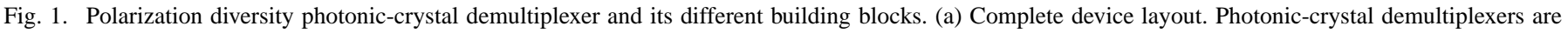

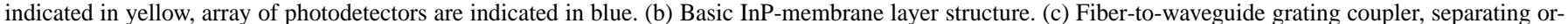

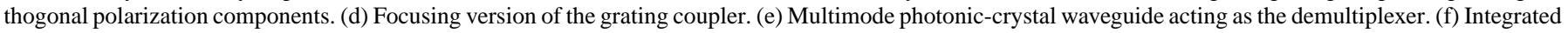
array of photodetectors at the demultiplexer channels.

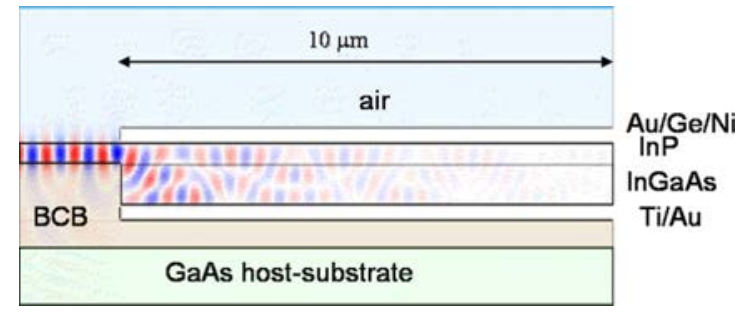

Fig. 2. Coupling from InP-membrane waveguide to underlying detector. An eigenmode expansion analysis provides the superimposed field.

1.54 at $1.55 \mu \mathrm{m})$ on a host-substrate [Fig. 1(b)]. This type of layer structure has a large index contrast which is comparable to SOI. Compact $\left(12 \times 12 \mu \mathrm{m}^{2}\right)$ surface grating couplers are used to inject light (near) vertically from a standard single-mode fiber (SMF-28) to a pair of nearly orthogonal waveguides [7], [8], ensuring a coupling efficiency around 50\% [25], [26]. Fig. 1(c) shows the original polarization diversity coupler that requires a relatively long $(>150 \mu \mathrm{m})$ taper. Alternatively, by using a curved crossed grating [Fig. 1(d)], the device footprint could be reduced substantially [27], [28]. Apart from facilitating polarization diversity another major benefit of the vertical coupling approach is the ability to perform wafer-scale testing, in stark contrast to edge-coupling methods [29]-[31]. This particular implementation of polarization splitting at the coupling stage is certainly the most compact. The focusing grating version results in a total size of the coupling/polarization diversity structure of $18.5 \times 30 \mu \mathrm{m}^{2}$. When, conversely, the polarizations are split and rotated at a later stage, nanophotonic high-index contrast designs have provided interesting solutions, but often these are not miniature enough. For example, in [32], a $600-\mu \mathrm{m}$-long polarization splitter/rotator was used. No details on fiber coupling were given. In [33], the combination of spot-size convertor (200 $\mu \mathrm{m}$, to lensed or high NA fiber [29]), polarization splitter $(10 \mu \mathrm{m})$, and polarization rotator $(30-60 \mu \mathrm{m})$ results in a total length of around $250 \mu \mathrm{m}$.

The second building block-the core of the device-is a photonic-crystal wavelength-division demultiplexer [Fig. 1(d)] based on multimode $\mathrm{PhC}$ waveguides. Its operating principle is extensively described in [34]-[36]. As the fiber core size $(\sim 8-10 \mu \mathrm{m})$ sets the lower limit of the in-coupler grating size, demultiplexing structures do not need to be much smaller per channel. In order to attain a sufficiently large photon residence time to meet Coarse WDM channel specifications (20-nm-intervals, or subintervals of it) within these $\sim 10-20 \mu \mathrm{m}$ of device size, it is desirable to use a resonant approach. The alternative "Phasar" spectrometer (AWG, etc.) approach is nonresonant and its footprint therefore scales with the square of the spectral resolution. For comparison, a InP based $4 \times 4$ AWG in [37] has a channel spacing of $3.2 \mathrm{~nm}$ and a footprint of $230 \times 330 \mu \mathrm{m}^{2}$. A $3 \times 9$ AWG in SOI in [15] has a footprint of $70 \times 60 \mu \mathrm{m}^{2}$ and a channel spacing of $11 \mathrm{~nm}$. The $4 \times 4$ AWG in $\alpha$-Si in [16] has a footprint of $40 \times 50 \mu \mathrm{m}^{2}$ with a channel spacing of $11 \mathrm{~nm}$. The InP-membrane PhC device shown here is also very compact and performs coarse-WDM demultiplexing with a standard channel spacing of $10 \mathrm{~nm}$, each wavelength channel directly feeding into an integrated waveguide detector [Fig. 1(e)]. Each channel needs to be around $30 \mu \mathrm{m}$ long, resulting in a footprint of $120 \times 5 \mu \mathrm{m}^{2}$ for a four-channel device. The wavelength spacing can be chosen at will, e.g., not regularly spaced nor in any particular ascending or descending order, which is a clear advantage of this realization. It also leaves room for unaffected through-channels that could be used for extended network management and other functions.

The third building block is an array of integrated p-i-n photodiodes [Fig. 1(f)] that are discussed next. 
(a)

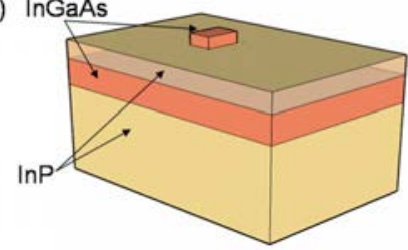

(c)

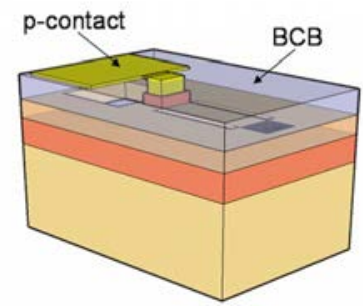

(e)

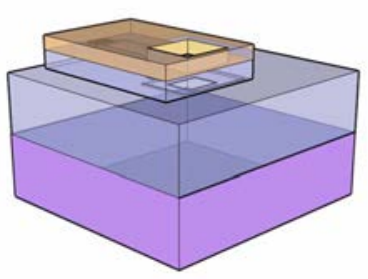

(b)

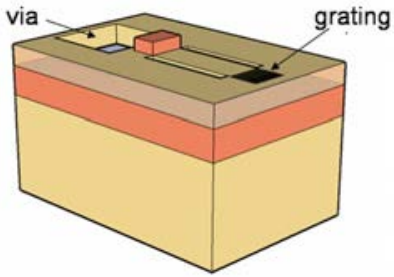

(d)

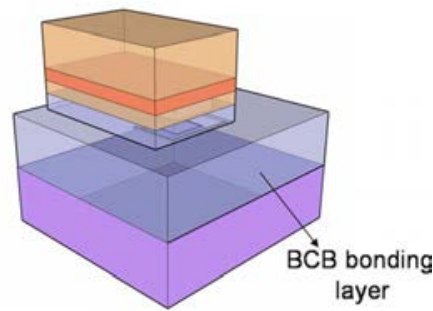

(f) n-contact

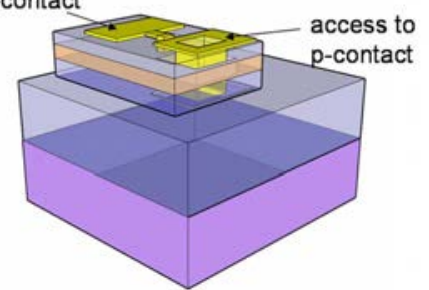

Fig. 3. Integration scheme and fabrication of the devices. (a) Detector mesa definition. (b) Definition and etching of gratings, waveguide, PhC devices and via holes aligned to the detector mesa. (c) Definition of the detector p-contact. Sample now ready for bonding. (d) Sample after DVS-BCB bonding. (e) Substrate and etch-stop layer removal of the InP-die. (f) Definition of detector n-contact and access to the p-contact through a via-hole.

\section{INTEGRATED PHOtodetectors ON INP-MEMBRANE}

\section{A. Principle}

The detector coupling arrangement is shown in Fig. 2.

Light guided in the InP-membrane refractively couples into an underlying InGaAs absorbing layer. In this type of structure, absorption losses in the metal contacts play an important role. As can be seen in Fig. 2, the light reflects back and forth between the two contact layers. While this ensures a sufficiently long path to ensure absorption in the thin InGaAs layer, it also incurs competing absorption losses in the metal contact. If the InGaAs layer were thicker, light could be absorbed along a shorter path, thereby, minimizing losses in the metal contacts. The thickness of the absorber layer influences also the speed of the detector. A thick absorber layer results in lower capacitance, but carrier transit times are increased [38]. The chosen InGaAs absorber thickness of $500 \mathrm{~nm}$ is a reasonable compromise between efficiency and speed and a detector length of $10 \mu \mathrm{m}$ is sufficient to absorb all the light.

\section{B. Integration Scheme and Fabrication}

The layer structure of the initial epitaxial material consists of (from top to bottom) an 80-nm highly p-doped InGaAs contact layer, a 500-nm intrinsic InGaAs absorbing layer, a 300-nm n-doped InP-membrane layer, and a 500-nm InGaAs etch-stop layer on an InP-substrate. The fabrication scheme is illustrated in Fig. 3. First, detector mesas are defined by optical lithography and (dry and wet) etching down to the InP-membrane layer [Fig. 3(a)]. Second, gratings, waveguides and $\mathrm{PhC}$ devices are defined by e-beam lithography and aligned to the detector mesas, then etched into an $\mathrm{SiO}_{2}$ hard mask. Also, large vias $\left(50 \times 50 \mu \mathrm{m}^{2}\right)$ are defined by optical lithography and etched into the hard mask. We use a two-step etch process for the InP-etching. First, we perform a 300-nm InP-etch $\left(\mathrm{CH}_{4}-\mathrm{H}_{2}\right.$ inductively coupled plasma reactive ion etching) for the vias and those devices requiring the full membrane etch, while protecting other areas (e.g., the gratings) under a photoresist cap. Afterwards, the cap is removed and all patterns are etched by another $90 \mathrm{~nm}$ in order to obtain the gratings. The complete pattern, after etching, is shown in Fig. 3(b).

In the next step, a 700-nm BCB layer is spin-coated onto the sample for passivation. After curing the $\mathrm{BCB}$, p-contact windows are opened, and a $\mathrm{Ti}-\mathrm{Au}(20 \mathrm{~nm} / 200 \mathrm{~nm})$ p-contact, also covering the vias, is deposited using lift-off [Fig. 3(c)].

The die is then bonded onto a GaAs host-substrate using another BCB layer that is approximately $1 \mu \mathrm{m}$ thick [Fig. 3(d)]. After curing for $1 \mathrm{~h}$ at $250{ }^{\circ} \mathrm{C}$ in a nitrogen atmosphere, the InP-substrate is removed (using lapping and wet etching) down to the etch-stop layer. The etch stop layer is then dissolved by wet etching [Fig. 3(e)].

Finally, another passivation BCB layer is spin-coated onto the sample. After curing, n-contact windows are opened and the access to the bottom p-contact is provided by etching the via (now filled with BCB) down to the p-contact. In the last step, a $\mathrm{Au}-\mathrm{Ge}-\mathrm{Ni}$ n-contact is deposited using lift-off [Fig. 3(f)].

\section{Detector Characterization}

We characterized the detectors by measuring the $I-V$ curves of the detectors for different optical input powers. The procedure is shown in Fig. 4. A standard cleaved single-mode fiber connected to a tunable laser is positioned above an input grating, at $10^{\circ}$ from vertical in order to avoid reflections. Light is first 
(a)

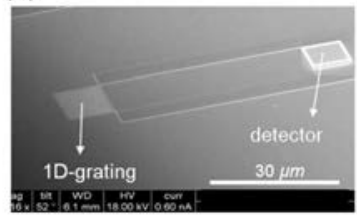

(c)

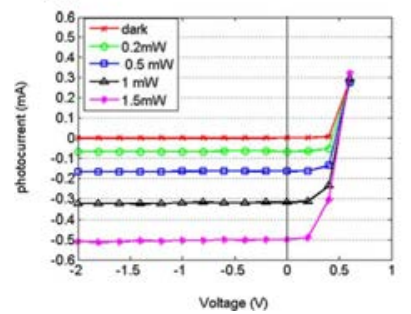

(b)

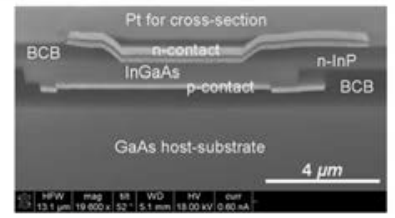

(d)

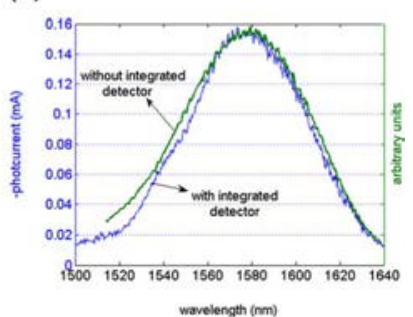

Fig. 4. Characterization of p-i-n photodetectors on InP-membrane. (a) Layout for characterizing the detectors (SEM-picture prior to bonding). Grating couplers are used for coupling from fiber to waveguide. (b) SEM-picture of a detector after cross section by Focused Ion Beam. (c) $I-V$ curves of the detector for different input powers. (d). Wavelength dependence of the grating coupler.

coupled to a waveguide by the grating [Fig. 4(a)] and then refractively coupled to the underlying detector [cross-section in Fig. 4(b)]. In this single-waveguide configuration, the gratings are almost $100 \%$ polarization selective [39], so we use birefringent fiber loops (Lefevre loops) [40] to select the TE-polarization (electric field parallel to the grating lines).

The results for a $12 \times 10 \mu \mathrm{m}^{2}$ detector are shown in Fig. 4(c). The dark current of the detector is $4 \mathrm{nA}$ at $0.5-\mathrm{V}$ reverse bias. After taking into account the loss in the polarization loops $(0.9$ $\mathrm{dB}$ ), the external responsivity (fiber-to-detector) is $0.4 \mathrm{~A} / \mathrm{W}$. The grating coupler efficiency is estimated to be $30 \%-40 \%$, which could be further increased by adding a bottom mirror to the grating [25]. The wavelength dependence of the grating coupler efficiency, measured with the integrated detector is shown in Fig. 4(d). The 1-dB optical bandwidth is $40 \mathrm{~nm}$. We have verified that this wavelength dependence is due to the grating coupler alone, by comparing this curve with a grating coupler spectrum measured without integrated detector. Both curves nearly coincide, and small differences are attributed to deviations in parameters between the different fabricated gratings.

\section{Photonic-Crystal DemultiPleXer}

We have applied the integration scheme described above to elaborate a compact photonic-crystal (PhC) demultiplexer (demux) with photodetectors (Fig. 5). The device is a membrane version of the demultiplexer described in [34]-[36]. Basically, it exploits resonant intermodal coupling at the mini-stopband (MSB) of a multimode PhC waveguide (here: "W5" type) [41]. The input signal is converted into a higher-order mode and then extracted through one side of the $\mathrm{PhC}$, which is made thinner in order to facilitate leakage of the mode [Fig. 5(a)]. Demux operation is obtained by adapting the $\mathrm{PhC}$ guide width locally, thereby tuning the MSB to the desired extraction wavelength. A section length of $\sim 30 \mu \mathrm{m}$ is sufficient for good extraction, resulting in an extremely compact device.

The device layout is shown in Fig. 5(b). Using a 1D-grating coupler, light from a tunable laser is again coupled into a membrane waveguide, feeding the $\mathrm{PhC}$ demultiplexer. The optical

(a)

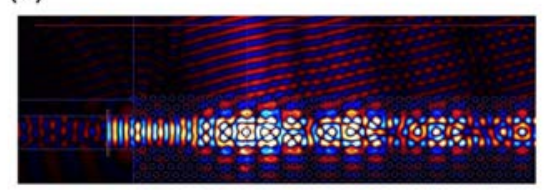

(b)

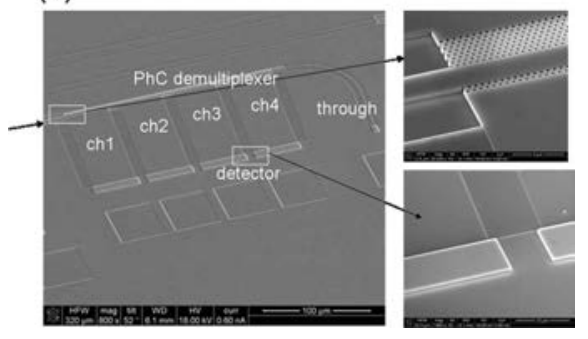

Fig. 5. Photonic-crystal demultiplexer based on multimode waveguides. (a) FDTD simulation, showing the extraction of higher order modes. (b) Layout of the device (SEM-picture prior to bonding).

(a)

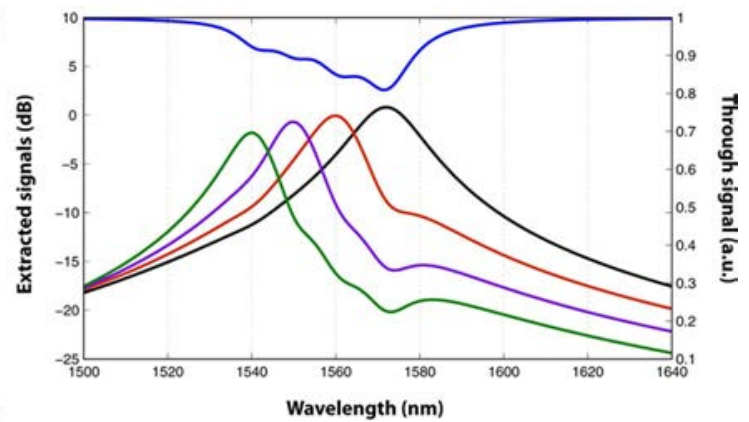

(b)

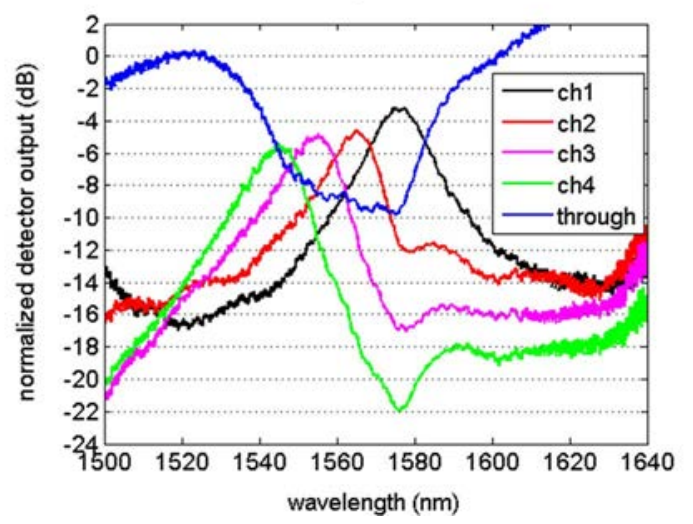

Fig. 6. (a) Typical output spectra obtained by Coupled Mode Theory. (b) Measurement of the photocurrent at the channel and through port detectors. Spectra are normalized to the grating coupler spectrum.

signals are extracted in four broad channels towards integrated photodiodes, where the photocurrent is generated. The through signal goes to another integrated detector. The results are shown in Fig. 6. Good agreement between simulation [Coupled Mode Theory, Fig. 6(a)] and experiment [Fig. 6(b)] is obtained. The crosstalk between $20 \mathrm{~nm}$-spaced channels (required for CWDM) is around 6-8 $\mathrm{dB}$, which can be improved further by engineering the transfer function of the MSB, e.g., through fine-tuning the size and number of holes of the $\mathrm{PhC}$ cladding through which the signal is extracted. 


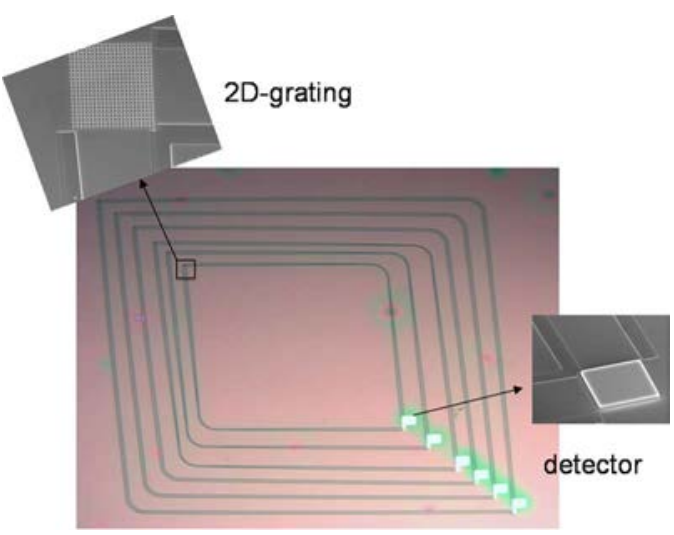

Fig. 7. Polarization diversity using 2D-gratings. Sample layout prior to bonding.

\section{POLARIZATION DiVERSITY COUPLERS}

\section{A. Principle}

Polarization diversity can be used in order to overcome the polarization sensitivity of nanophotonic devices. In this approach, the two orthogonal polarization components of the incident light are split, and one is rotated by $90^{\circ}$, resulting in two channels of identical polarization (here: TE). These two beams then feed two identical (polarization sensitive) devices. At the output, one polarization component is rotated by $90^{\circ}$, and both (now orthogonally polarized) signals are recombined, without interferences, at the exit. In our device, we exploit 2D-grating couplers that perform polarization splitting, and polarization rotation function in the same structure [7], [8].

\section{B. Polarization Diversity from Fiber to Detector}

First, we implemented polarization diversity between an input fiber and a detector. The layout is shown in Fig. 7. Six nested independent fiber-to-detector optical links are shown. Each time, a 2D-grating is placed at the intersection of two (near) orthogonal waveguides. The two orthogonal polarization components from the fiber couple to the TE-mode of their associated waveguide which then feed into adjacent sides of the photodiode detector pad.

To assess the polarization dependence of this arrangement, the photocurrent is measured while randomly varying the polarization state of the input light using polarization loops. The ratio $I_{\max } / I_{\min }$ defines the polarization dependent loss (PDL). The PDL measured at wavelengths of interest is shown in Fig. 8(a). The minimal PDL is $0.2 \mathrm{~dB}$ and the PDL is smaller than $1 \mathrm{~dB}$ over more than $45 \mathrm{~nm}$. The PDL increases rapidly on the long wavelength side, while it only increases slowly on the short wavelength side, as explained below. The variation in photocurrent with a random variation of the polarization state over time is shown in Fig. 8(b). In this case, the fiber-to-detector responsivity is $0.23 \mathrm{~A} / \mathrm{W}$. This value is lower than the $0.4 \mathrm{~A} / \mathrm{W}$ of the 1D-grating+detector case (Section III-C), which is caused by a slightly lower grating coupler efficiency and losses in the bends.

The wavelength dependence of the PDL is caused by the tilt of the fiber. This tilt along the bisection line of the grating is needed to cut off second-order reflection. The waveguides then (a)
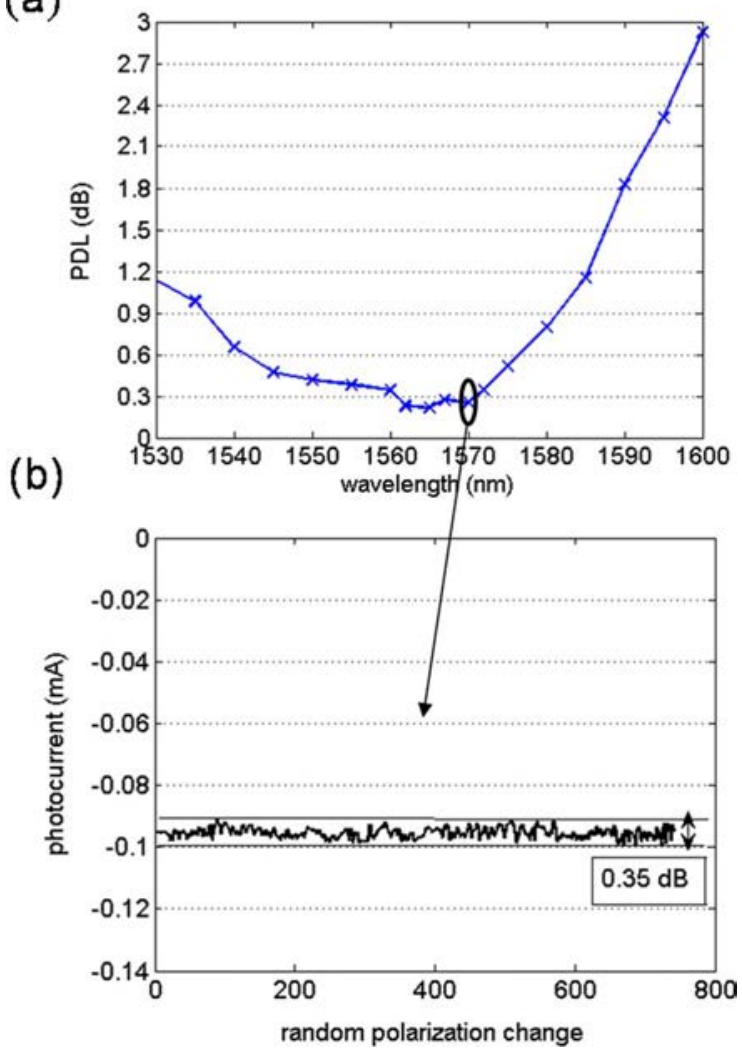

Fig. 8. Measurement of the PDL. (a) Wavelength dependence. (b) Detector photocurrent under random polarization change $(\lambda=1570 \mathrm{~nm})$.

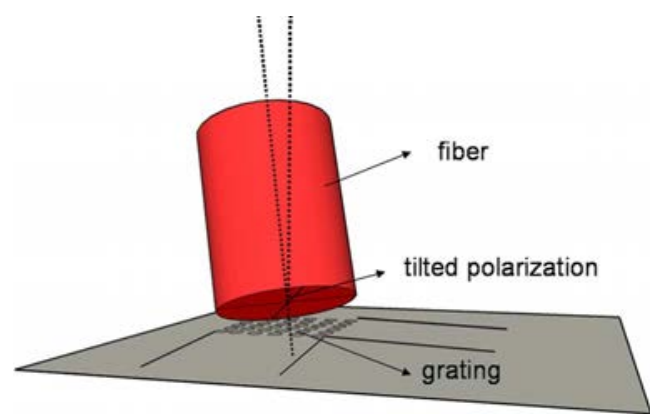

Fig. 9. Configuration for polarization diversity coupling. The fiber is tilted along the bisection line of the grating, and the waveguides are tilted inwards.

have to be rotated slightly inwards [8]. This inward tilt of the waveguides is $2.8^{\circ}$ for the measured device and can also be seen in Fig. 7. In Fig. 9, we show the coupling configuration. As a result of the fiber tilt, both orthogonal polarizations do not experience the same coupling efficiency, as one polarization is tilted out of a plane parallel to the grating. This also causes the coupling curves for both polarizations to shift in wavelength, which causes a wavelength dependence of the PDL. In addition, the optimal waveguide angle is not the same for both polarizations, causing a difference in transmitted power. We have verified this experimentally. In Fig. 10, we show the wavelength dependence of the coupling efficiency (which is proportional to the photocurrent measured at the detector) for the two input polarizations where the transmission (photocurrent) is maximum and minimum at a wavelength of $1600 \mathrm{~nm}$ (where the PDL is 


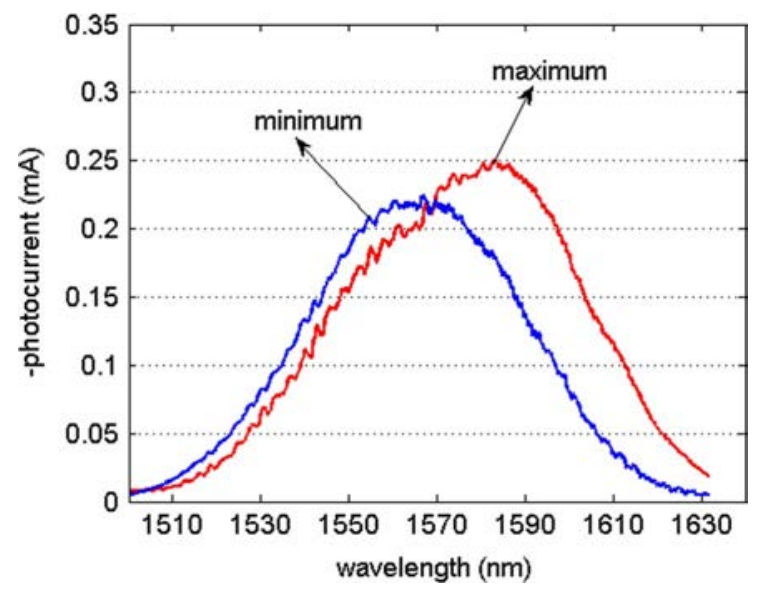

Fig. 10. Wavelength dependence of the coupling efficiency for input polarizations where transmission is maximum and minimum at $\lambda=1600 \mathrm{~nm}$.

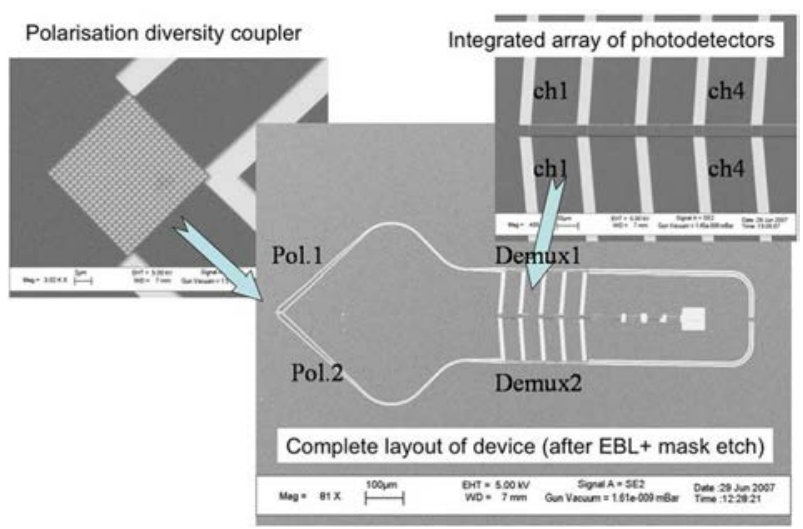

Fig. 11. Polarization diversity $\mathrm{PhC}$ demux with integrated photodetectors.

high). Therefore, we aligned the fiber for minimum PDL, which occurs at a wavelength of $1570 \mathrm{~nm}$. The wavelength was then set to $1600 \mathrm{~nm}$, the polarization was set for maximum photocurrent and the wavelength dependence of the coupling efficiency was measured. Afterwards, this was repeated for the input polarization where the photocurrent is minimal at $1600 \mathrm{~nm}$ (at the same fiber alignment). A wavelength shift of $18 \mathrm{~nm}$ is observed between both curves. At the wavelength where both curves cross (i.e., $1570 \mathrm{~nm}$ ), the PDL is minimal. At longer wavelengths, the PDL increases rapidly since the ratio between maximum and minimum signal becomes large. At shorter wavelengths, the PDL is increasing slowly, since the maximum and minimum signals lie closer together.

\section{Polarization Diversity PhC Demux}

Finally, we implemented a polarization diversity version of the PhC demultiplexer from Section IV. The layout is shown in Fig. 11. A 2D-grating coupler $\left(12 \times 12 \mu \mathrm{m}^{2}\right)$ is used for coupling to the TE-modes of two (near) orthogonal waveguides. The demultiplexer is duplicated and the corresponding channel outputs and through signals of both demultiplexer arms are combined into common integrated detectors. The detector photocurrent is measured for three channels (the detector of channel 4 was damaged) as well as the through signal. The proper operation of the

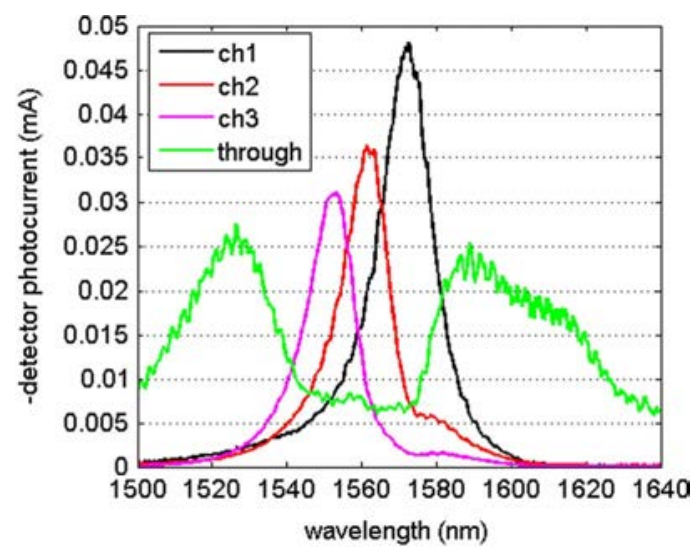

Fig. 12. Detector output for the polarization diversity $\mathrm{PhC}$ demux (not normalized to the grating coupler, linear scale).

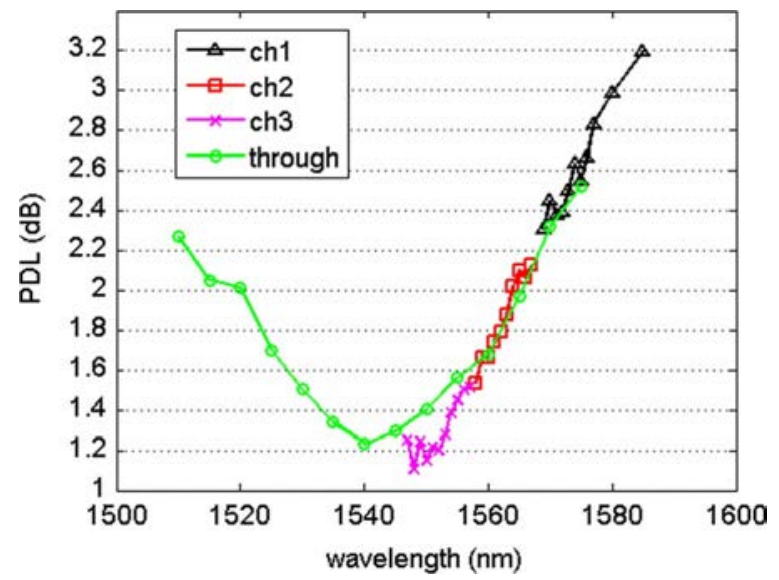

Fig. 13. PDL as a function of wavelength for the polarization diversity $\mathrm{PhC}$.

device is shown in Fig. 12. As before, the difference in photocurrent between the different channel detectors is caused by the wavelength dependence of the grating coupler.

The corresponding PDL measurement is shown in Fig. 13, again for the three channels and the through signal. The minimum PDL is $1.1 \mathrm{~dB}$, and a wavelength dependence similar to Fig. 8(a) is obtained. The PDL is larger for this device, which is due to the increased complexity of the circuit. To reduce the PDL, both arms (one for each orthogonal input polarization) would need to be as identical as possible, which is not easy to achieve, since each arm includes a single-mode bend $(500 \mathrm{~nm}$ wide), a strip waveguide-to-PhC transition, and shared detectors.

\section{CONCLUSION}

We have demonstrated a number of grating-coupled functional devices integrated with photodetectors on an InP-membrane. The external responsivity (SMF-28 fiber-to-detector) is $0.4 \mathrm{~A} / \mathrm{W}$. Using the same integration scheme, a very compact photonic-crystal demultiplexer with photodiodes was obtained. Future work will concentrate on measuring the bandwidth of the detectors and reducing the crosstalk of the demultiplexer. We have also implemented polarization diversity using 2D-grating couplers. A simple configuration from fiber to detector results in a very low PDL of $0.2 \mathrm{~dB}$. This value increases to $1.1 \mathrm{~dB}$ when 
adding the $\mathrm{PhC}$ demultiplexer (with integrated photodiodes) to this polarization diversity scheme. We believe that this value can be decreased by taking special care to the identical fabrication of the two arms in the functional device. These improvements (PDL and crosstalk) will confirm that a compact photonic-crystal integrated device is a genuine technological option for miniature telecom heads at both sides of the access networks (user and metro).

\section{ACKNOWLEDGMENT}

The Fraunhofer Institut für Nachrichtentechnik, Heinrich-Hertz Institut, Berlin, Germany, is acknowledged for providing the $\mathrm{InP}$ epiwafers.

\section{REFERENCES}

[1] Y. Akahane, T. Asano, B. S. Song, and S. Noda, "High-Q photonic nanocavity in a two-dimensional photonic crystal," Nature, vol. 425, pp. 944-947, 2003.

[2] T. Tanabe, M. Notomi, E. Kuramochi, A. Shinya, and H. Taniyama, "Trapping and delaying photons for one nanosecond in an ultrasmall high-Q photonic-crystal nanocavity," Nature Photonics, vol. 1, pp. 49-52, 2007.

[3] M. T. Hill, Y. S. Oei YS, B. Smalbrugge, Y. Zhu, T. De Vries, P. J. Van Veldhoven, F. W. M. Van Otten, T. J. Eijkemans, J. P. Turkiewicz, H. De Waardt, E. J. Geluk, S. H. Kwon, Y. H. Lee, R. Notzel, and M. K. Smit, "Lasing in metallic-coated nanocavities," Nature Photon., vol. 1, pp. 589-594, 2007.

[4] A. C. Tamboli, E. D. Haberer, R. Sharma, K. H. Lee, S. Nakamura, and E. L. Hu, "Room-temperature continuous-wave lasing in $\mathrm{GaN} / \mathrm{InGaN}$ microdisks," Nature Photon., vol. 1, pp. 61-64, 2007.

[5] K. Srinivasan and O. Painter, "Linear and nonlinear optical spectroscopy of a strongly coupled microdisk-quantum dot system," Nature, vol. 450, pp. 862-865, 2007.

[6] H. Benisty, C. Weisbuch, D. Labilloy, M. Rattier, C. J. M. Smith, T. F. Krauss, R. M. De La Rue, R. Houdré, U. Oesterle, and D. Cassagne, "Optical and confinement properties of two-dimensional photonic crystals," J. Lightw. Technol., vol. 17, no. 11, pp. 2063-2077, Nov. 1999.

[7] D. Taillaert, H. Chong, P. I. Borel, L. H. Frandsen, R. M. De La Rue, and R. Baets, "A compact two-dimensional grating coupler used as a polarization splitter," IEEE Photon. Technol. Lett., vol. 15, no. 9, pp. 1249-1251, Sep. 2003.

[8] F. Van Laere, T. Stomeo, D. Taillaert, G. Roelkens, D. Van Thourhout, T. F. Krauss, and R. Baets, "Efficient polarization diversity grating couplers in bonded InP-membrane," IEEE Photon. Technol. Lett., vol. 20, no. 4, pp. 318-320, Feb. 15, 2008.

[9] G. Roelkens, J. Brouckaert, D. Van Thourhout, R. Baets, R. Notzel, and M. Smit, "Adhesive bonding of InP/InGaAsP dies to processed silicon-on-insulator wafers using DVS-bis-benzocyclobutene," J. Electrochem. Soc., vol. 153, pp. G1015-G1019, 2006.

[10] B. S. Song, S. Noda, and T. Asano, "Photonic devices based on in-plane hetero photonic crystals," Science, vol. 300, pp. 1537-1537, 2003.

[11] M. Notomi, A. Shinya, S. Mitsugi, E. Kuramochi, and H. Ryu, "Waveguides, resonators, and their coupled elements in photonic crystal slabs," Opt. Express, vol. 12, pp. 1551-1561, 2004.

[12] M. Settle, M. Salib, A. Michaeli, and T. F. Krauss, "Low loss silicon on insulator photonic crystal waveguides made by $193 \mathrm{~nm}$ optical lithography," Opt. Express, vol. 14, pp. 2440-2445, 2006.

[13] Y. A. Vlasov and S. J. McNab, "Losses in single-mode silicon-on-insulator strip waveguides and bends," Opt. Express, vol. 12, pp. 1622-1631, 2004.

[14] W. Bogaerts, P. Dumon, D. Van Thourhout, D. Taillaert, P. Jaenen, J. Wouters, S. Beckx, V. Wiaux, and R. Baets, "Compact wavelength-selective functions in silicon-on-insulator photonic wires," J. Sel. Topics Quantum Electron., vol. 12, no. 6, pp. 1394-1401, Nov.-Dec. 2006.

[15] K. Sasaki, F. Ohno, A. Motegi, and T. Baba, "Arrayed waveguide grating of $70 \times 60 \mu \mathrm{m}^{2}$ size based on Si photonic wire waveguides," Electron. Lett., pp. 801-802, 2005.

[16] D. Dai, L. Liu, L. Wosinski, and S. He, "Design and fabrication of ultra-small overlapped AWG demultiplexer based on $\alpha$-Si nanowire waveguides," Electron. Lett., vol. 42, pp. 400-402, 2006.
[17] W. Bogaerts, D. Taillaert, P. Dumon, D. Van Thourhout, and R. Baets, "A polarization-diversity wavelength duplexer circuit in silicon-on-insulator photonic wires," Opt. Express, vol. 15, pp. 1567-1578, 2007.

[18] T. Niemi, L. H. Frandsen, K. K. Hede, A. Harpoth, P. I. Borel, and M. Kristensen, "Wavelength-division demultiplexing using photonic crystal waveguides," IEEE Photon. Technol. Lett., vol. 18, no. 1, pp. 226-228, Jan. 2006.

[19] Y. Akahane, T. Asano, H. Takano, B.-S. Song, Y. Takana, and S. Noda, "Two-dimensional photonic-crystal-slab channel-drop filter with flat-top response," Opt. Express, vol. 13, pp. 2512-2530, 2005.

[20] G. Masini, G. Capellini, J. Witzens, and C. Gunn, "A four-channel, 10 Gbps monolithic optical receiver in $130 \mathrm{~nm}$ CMOS with integrated Ge waveguide photodetectors," Proc. OFC 2007, PDP31.

[21] P. R. A. Binetti, X. J. M. Leijtens, M. Nikoufard, T. de Vries, Y. S. Oei, L. Di Cioccio, J.-M. Fedeli, C. Lagahe, R. Orobtchouk, C. Seassal, J. Van Campenhout, D. Van Thourhout, P. J. van Veldhoven, R. Notzel, and M. K. Smit, "InP-based membrane photodetectors for optical interconnects to Si," in Proc. IEEE LEOS Int. Conf. Group IV Photonics, 2007, WB4.

[22] A. W. Fang, R. Jones, H. Park, O. Cohen, O. Raday, M. J. Paniccia, and J. E. Bowers, "Integrated AlGaInAs-silicon evanescent racetrack laser and photodetector," Opt. Express, vol. 15, pp. 2315-2322, 2007.

[23] G. Roelkens, D. Van Thourhout, R. Baets, R. Notzel, and M. Smit, "Laser emission and photodetection in an InP/InGaAsP layer integrated on and coupled to a Silicon-on-Insulator waveguide circuit," Opt. Express, vol. 14, pp. 8154-8159, 2006.

[24] F. Van Laere, T. Stomeo, M. Ayre, C. Cambournac, H. Benisty, D. Van Thourhout, T. F. Krauss, and R. Baets, "Multifunctional photonic crystal compact demux-detector on InP," Proc. OFC 2008, OThM5.

[25] F. Van Laere, G. Roelkens, M. Ayre, J. Schrauwen, D. Taillaert, D. Van Thourhout, T. F. Krauss, and R. Baets, "Compact and highly efficient grating couplers between optical fiber and nanophotonic waveguides," J. Lightw.Technol., vol. 25, no. 1, pp. 151-156, Jan. 2007.

[26] G. Roelkens, D. Van Thourhout, R. Baets, R. Notzel, and M. K. Smit, "High efficiency Silicon-on-insultator grating coupler based on a polysilicon overlay," Opt. Express, vol. 14, 2007.

[27] F. Van Laere, T. Claes, J. Schrauwen, S. Scheerlinck, W. Bogaerts, D. Taillaert, L. O'Faolain, D. Van Thourhout, and R. Baets, "Compact focusing grating couplers for silicon-on-insulator integrated circuits," IEEE Photon. Technol. Lett., vol. 19, no. 23, pp. 1919-1921, Dec. 2007

[28] F. Van Laere, W. Bogaerts, P. Dumon, G. Roelkens, D. Van Thourhout, and R. Baets, "Focusing polarization diversity grating couplers in silicon-on-insulator," J. Lightw. Technol, submitted for publication.

[29] T. Shoji, T. Tsuchizawa, T. Watanabe, K. Yamada, and H. Morita, "Low loss mode size converter from $0.3 \mu \mathrm{m}$ square $\mathrm{Si}$ wire waveguides to singlemode fibres," Electron. Lett., vol. 38, pp. 1669-1670, 2002.

[30] S. J. McNab, N. Moll, and Y. A. Vlasov, "Ultra-low loss photonic integrated circuit with membrane-type photonic crystal waveguides," Opt. Express, vol. 11, pp. 2927-2939, 2003.

[31] V. R. Almeida, R. R. Panepucci, and M. Lipson, "Nanotaper for compact mode conversion," Opt. Lett., vol. 28, pp. 1302-1304, 2003.

[32] T. Barwicz, M. R. Watts, M. Popovic, P. T. Rakich, L. Socci, F. X. Kartner, E. P. Ippen, and H. I. Smith, "Polarization-transparent microphotonic devices in the strong confinement limit," Nature Photon., vol. 1, pp. 57-60, 2007.

[33] H. Fukuda, K. Yamada, T. Tsuchizawa, T. Watanabe, H. Shinojima, and S. Itabashi, "Silicon photonic circuit with polarization diversity," Opt. Express, vol. 16, pp. 4872-4880, 2008.

[34] E. Viasnoff-Schwoob, C. Weisbuch, H. Benisty, C. Cuisin, E. Derouin, O. Drisse, G. H. Duan, L. Legouezigou, O. Legoazigou, F. Pommereau, S. Golka, H. Heidrich, H. J. Hensel, and K. Janiak, "Compact wavelength monitoring by lateral outcoupling in wedged photonic crystal multimode waveguides," Appl. Phys. Lett., vol. 86, pp. 101107-, 2005.

[35] L. Martinelli, H. Benisty, O. Khayam, G. H. Duan, H. Heidrich, and K. Janiak, "Analysis and optimization of compact demultiplexer monitor based on photonic crystal waveguide," J. Lightw. Technol., vol. 25, no. 9, pp. 2385-2394, Sep. 2007.

[36] L. Martinelli, H. Benisty, O. Drisse, E. Derouin, F. Pommereau, O. Legouézigou, and G. H. Duan, "Impact of lithographic grid irregularity assessed on photonic crystal device selectivity," IEEE Photon. Technol. Lett., vol. 19, no. 5, pp. 282-284, Mar. 2007.

[37] Y. Barbarin, X. J. M. Leijtens, E. A. J. M. Bente, C. M. Louzao, J. R. Kooiman, and M. K. Smit, "Extremely small AWG demultiplexer fabricated on InP by using a double-etch process," IEEE Photon. Technol. Lett., vol. 16, no. 11, pp. 2748-2480, Nov. 2004. 
[38] R. J. Deri, "Monolithic integration of optical waveguide circuitry with III-V photodetectors for advanced lightwave receivers," J. Lightw. Technol., vol. 11, no. 8, pp. 1296-1313, Aug. 1993.

[39] D. Taillaert, F. Van Laere, M. Ayre, W. Bogaerts, D. Van Thourhout, P. Bienstman, and R. Baets, "Grating couplers for coupling between optical fibers and nanophotonic waveguides," Jpn. J. Appl. Phys. 1, Regul. Pap. Brief Commun. Rev. Pap., vol. 45, pp. 6071-6077, 2006.

[40] H. C. Lefevre, "Single-mode fiber fractional wave devices and polarization controllers," Electron. Lett., vol. 16, pp. 778-780, 1980.

[41] S. Olivier, H. Benisty, C. J. M. Smith, M. Rattier, C. Weisbuch, and T. F. Krauss, "Transmission properties of two-dimensional photonic crystal channel waveguides," Opt. Quantum Electron., vol. 34, pp. 171-181, 2002.

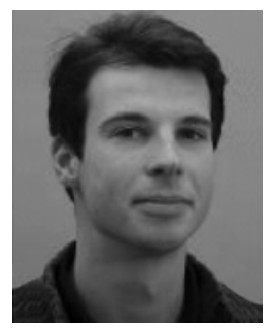

Frederik Van Laere (S'05) received the degree in electrical engineering from Ghent University, Gent, Belgium, in 2004, where he is currently working towards the Ph.D. degree in electrical engineering in the Department of Information Technology. He is currently working on design, fabrication, and characterization of nanophotonic waveguide components and their integration with active functionality.

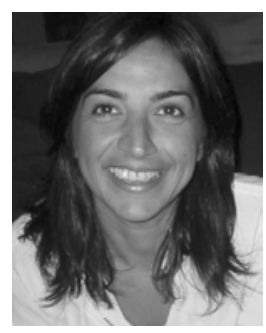

Tiziana Stomeo received the Laurea degree in electronic engineering from the Politecnico di Bari, Italy, in 2002 and the Ph.D. degree in innovative materials and technologies from the National Nanotechnology Laboratory (NNL), CNR-INFM, Italy, and the Institute of Advanced Interdisciplinary Studies, Università del Salento, Italy, in 2006. Her research activity was focused on the development of high-resolution nanotechnological processes of photonic-crystal devices based on different materials (dielectrics, GaAs/ AlGaAs and organics).

From 2006 to 2007, she did postdoctoral work with the Microphotonic Research Group, School of Physics and Astronomy, University of St. Andrews U.K., where she was involved in the fabrication of photonic microstructures in InP-based material for polarization and wavelength control, as well as structures for coupling between nanostructured waveguides and optical fibers. She is currently a Researcher with the Innovative Materials and Nanodevices Division at NNL, where she is involved in the design and fabrication of photonic-crystal-based devices for both bio- and telecommunications applications.

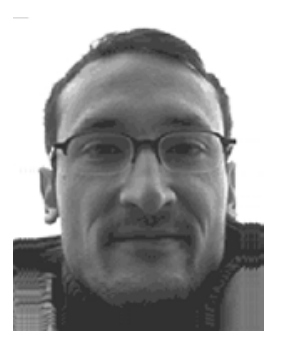

Cyril Cambournac was born in Saint-Mandé, France, in 1975. He received the B.S. degree in physics and the Ph.D. degree in engineering sciences from the Franche-Comté University, Besançon, France, in 1998 and 2003, respectively.

From 2002 to 2005, he joined the Service d'Optique et d'Acoustique of the Applied Sciences Faculty of Free University of Brussels, Brussels, Belgium, as a Postdoctoral Fellowship, studying nonlinear spatial optical phenomena, and particularly those related to soliton beams and instabilities in Kerr and non-Kerr media (photovoltaic crystals and liquid crystals). He is now a CNRS Research Fellow at the Laboratoire Charles-Fabry de l'Institut d'Optique, Palaiseau, France, and works in the experimental exploration of electromagnetic phenomena in linear and nonlinear photonic-crystal-type structures. His Ph.D. dissertation "Spatial Instabilities in Kerr Media: Arrays of Spatial Solitons and Symmetry Breaking of Multimode Solitons in a Planar Waveguide" was awarded the 2003 Saint-Gobain Young Researcher Prize from the French Physical Society.

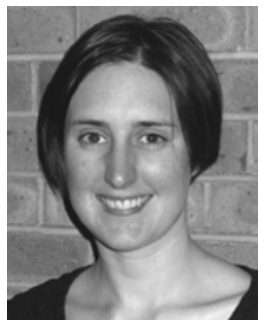

Melanie Ayre received the M.Eng. (first-class Hons.) degree from the University of Glasgow, U.K., in 2002 and the Ph.D. degree from the Microphotonics and Photonic Crystals group at the University of St. Andrews, U.K. in 2006. Her research work was on design, simulation, fabrication, and characterization of photonic-crystal-based devices.

She then joined the Laboratoire Charles-Fabry de l'Institut d'Optique, Palaiseau, France, as a Postdoctoral Researcher, continuing work on photonic-crystal type devices.

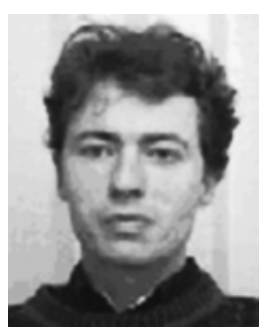

Romain Brenot was born in L'Hay-Les-Roses, France, in 1972. He received the Ph.D. degree from Ecole Polytechnique, France, in 2000, for work on transport properties of microcrystalline silicon.

$\mathrm{He}$ is currently working at Alcatel-Thales III-V Lab on design and characterization of active optoelectronic devices.

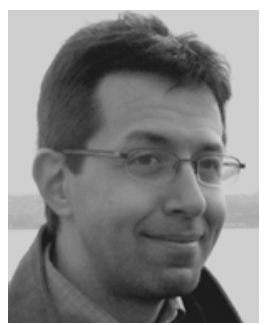

Henri Benisty (M'06) received the Ph.D. degree from University Paris 6, Paris, France, in 1989. His research work was on accumulation layers at $\mathrm{Si}$ interfaces.

He was with the Ecole Normale Supérieure, France, from 1982 to 1987. His research topics have been first nanostructure growth and physics (Thomson, Orsay) and lamellar III-VI compounds (Paris 6 University, Paris, France). Since 1994, he has been involved in research on microcavities (mainly for LEDs) and in photonic crystals in two dimensions on III-V in laboratory PMC, École Polytechnique, Palaiseau,France. He was with the University of Versailles until 2002 and is currently with the Laboratoire Charles Fabry de l'Institut d'Optique, Palaiseau, France. He currently investigates applications of PhCs to LEDs, biophotonics, and miniature photonic integrated circuits. He co-founded the biochip-related startup Genewave, Evry/Palaiseau, France.

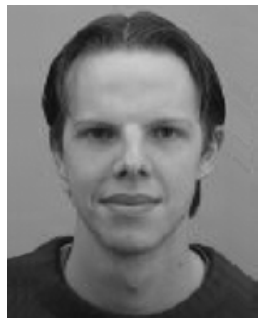

Günther Roelkens (S'02-M'06) was born in Ghent, Belgium, in 1979. He received the Electronics Engineer degree (with highest honors) and the Ph.D. degree from Ghent University, Belgium, in 2002 and 2007, respectively. His Ph.D. work was in the field of heterogeneous III-V/silicon photonics. In this work, the technology for integrating III-V material on top of silicon-on-insulator waveguide circuits was developed and the integration of thin film III-V laser diodes and photodetectors on top of and coupled to the SOI waveguide circuit was demonstrated.

Since 2002, he has been working in the Photonics Research Group at Ghent University, where he is now a Postdoctoral Researcher in the same group.

Dr. Roelkens received the Barco/FWO award for his Master's thesis titled "Ring Resonators for Photonic IC's Based on III-V Semiconductors." 


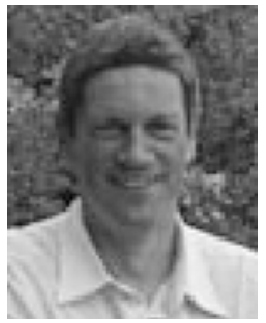

Thomas F. Krauss received the Dipl.-Ing. degree in photographic engineering (FH Koeln, Germany) in 1989 based on a diploma thesis conducted at IBM, Yorktown Heights, NY. He received the Ph.D. degree in the area of semiconductor ring lasers from the University of Glasgow, U.K., in 1992.

$\mathrm{He}$ initiated the field of semiconductor photonic crystals in the United Kingdom. He gained SERC and Royal Society Research Fellowships in 1993 and 1995, respectively, in support of this work and has since established a reputation worldwide, as evidenced by the large number of invited talks he presents at international level (10-15 such presentations per year). He is grant holder of several SFC, EPSRC, EU, and industrially sponsored research projects, coordinated EU-FP5 "PICCO" and leads the current EU-FP6 "SPLASH," both studying fundamental and applied aspects of photonic crystals. He collaborates strongly in Europe, especially through the EU-FP6 "epixnet" network and overseas, with the Australian CUDOS consortium. His 15-strong group operate the nanofabrication facility at St. Andrews, including electron beam and photolithography, wet and dry etching, thin film deposition as well as a characterization suite for active and passive microphotonic devices.

Prof. Krauss was elected a Fellow of the Institute of Physics on 2001 and the Royal Society of Edinburgh in 2002.

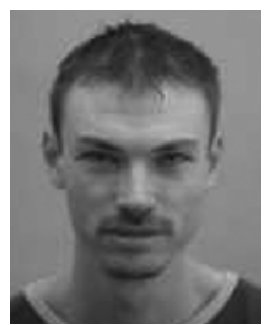

Dries Van Thourhout (M'98) received the Physical Engineering degree and the Ph.D. degree from Ghent University, Belgium, in 1995 and 2000, respectively.

From October 2000 to September 2002, he was with Lucent Technologies, Bell Laboratories, Murray Hill, NJ, working on the design, processing, and characterization of InP/InGaAsP monolithically integrated devices. In October 2002, he joined the Department of Information Technology (INTEC), Ghent University, Belgium, where he is currently a member of the permanent staff of the Photonics Group. He is Lecturer or Co-Lecturer for four courses within the Ghent University Master's in Photonics program. He is also coordinating the cleanroom activities of the research group. His research focuses on the design, fabrication, and characterization of integrated photonic devices. Main topics involve silicon nanophotonic devices, heterogeneous integration of InP-on-Silicon, and integrated InP-based optical isolators. In addition, he is working on the development of new fabrication processes for photonic devices, e.g., based on focused ion beam etching and die-to-wafer bonding. He holds three patents, has authored and coauthored over 60 journal papers, and has presented invited papers at several major conferences.

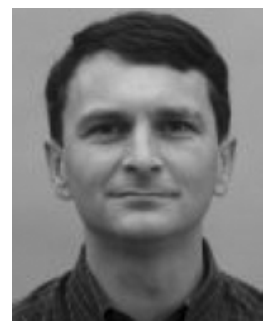

Roel Baets (M'88-SM'96-F'07) received the Electrical Engineering degree from Ghent University, Belgium, in 1980, the M.Sc. degree in electrical engineering from Stanford University, Stanford, CA, in 1981, and the Ph.D. degree from Ghent University in 1984.

Since 1981, he has been with the Department of Information Technology (INTEC) of Ghent University. Since 1989, he has been a Professor in the engineering faculty of Ghent University. From 1990 to 1994, he was also a part-time professor at the Technical University of Delft, The Netherlands. Since 2004, he has also been a parttime professor at the Technical University of Eindhoven. He has mainly worked in the field of photonic components. With about 250 journal publications and 500 conference papers as well as about 15 patents, he has made contributions to research on semiconductor laser diodes, passive guided wave and grating devices and to the design and fabrication of photonic ICs, both in III-V semiconductors and in silicon. He leads the Photonics Research Group at Ghent University-INTEC (associated laboratory of IMEC), which focuses on new concepts for photonic components and circuits for optical communication, optical interconnect, and optical sensing. He has been involved in various European research projects and has been coordinator of some of them. Currently, he coordinates the European Network of Excellence ePIXnet.

Dr. Baets is a member of the Optical Society of America (OSA), the IEEE Lasers \& Electro-Optics Society (LEOS), SPIE, and the Flemish Engineers Association. He has been member of the program committees of OFC, ECOC, the IEEE Semiconductor Laser Conference, ESSDERC, CLEO-Europe, the LEOS Annual Meeting, Photonics Europe, and ECIO. He was Chairman of the IEEE LEOS-Benelux Chapter from 1999 to 2001. From 2003 to 2005, he was an elected member of the Board of Governors of IEEE LEOS. 